\title{
The Research and Practice of the Training and Innovation of the Professional Skills and Cultivation of Talents
}

\author{
Shufeng Jiang, Fengjuan Wang, Rui Fan and Lili Liu \\ Institutions of mechanical and electrical engineering, qiqihar university 100161
} Keywords: Promote education quality; School and business cooperation; New technology ; Train
skilled personnel; enterprise competitions

\begin{abstract}
Because of our country in recent years to carry out the cooperation between colleges and higher application talent cultivation mode reform innovation, Brings along the changes of the teaching mode of industrialization of higher and newer, In the process of the higher vocational institutions into enterprises expand faster than bachelor colleges practice level, Make social cognition to the auto service industry is in repair maintenance, Low level service system that cannot ascend to reach the advanced countries for higher auto service talented person's cognition, Affect the industry higher professionals inflows and skills improve, So we analyzed 2016-2017 university-enterprise cooperation and domestic innovative game data, Data mining for information to guide the direction of teaching reform,Develop the educational reform of "school enterprise -competition", "school -competition- enterprise", "enterprise-competition- the school" the practice of the closed-loop collaborative innovation development platform, To develop "understand technology, Will begin, Will be written" new craftsman as the goal,Namely "educational reform content university-enterprise cooperation" model, The auto service professional higher skills training and promote enterprise technology have theory value and practice.
\end{abstract}

\section{Introduction}

The past mechanical engineering) (including automobile service engineering talents cultivation areas, at the time of training professional talents in higher vocational colleges, the most important key point is to take the market as the guidance, the market need what kind of car applied talents, the corresponding training is consistent with the market demand for professional talents, higher vocational education and the market demand to reach an agreement finally. With the cooperation of the automobile enterprises, we can set up order classes in higher vocational colleges and help upgrade teaching equipment in higher vocational colleges. These upgraded teaching equipment not only enable higher vocational colleges to complete the automobile vocational skills competition, but also make the practical teaching of higher vocational colleges better run [1]. The innovative application of "university-enterprise cooperation, teaching competition combination and customized training" will enable enterprises, colleges and competition organizers to achieve a win-win situation and form a virtuous circle of development. Undergraduate class colleges and universities attach importance to theoretical research and technology development, apparently in the process of teaching practice and enterprise demand, competition to participate in activities such as gap, cause undergraduate employment rate is lower than the higher vocational colleges, students' employment after adaptability problems such as lower than that of higher vocational students.

\section{Analysis of the status quo of gradient inequality in the development of labor, education and competition}

In the aspect of teaching reform, the university-enterprise cooperation of fusion innovation is suitable for the high vocational colleges with strong vitality and actively absorbing the advanced experience at home and abroad. The preference in the conventional teaching in higher vocational colleges to instill automobile industry standards and ideas of vocational skills competition, and through the form of university-enterprise cooperation talents advantage into the whole industry chain thoroughly play out [2]. In the end, by combining the advantages of school, enterprise and competition, we should update and optimize teaching methods, teaching AIDS and teaching system 
in a timely manner. In the field of competition development, fusion innovation is applicable to professional skills competitions with deep cooperation with enterprises.

Bachelor degree or above in the talent cultivation system, takes the theory in-depth explanation, employment guidance for the design of mechanical equipment and the related application field of derivative product development, the traditional classroom centered machinery professional development model is no longer adapt to the market demand. For example, we count the universities, teachers and students of the 2016 innovation practice ability competition.

Table 1 data summary table of innovation competition of thousands of enterprises in 2016.

\begin{tabular}{ccccc}
\hline $\begin{array}{c}\text { point } \\
\text { game category }\end{array}$ & $\begin{array}{c}\text { northern } \\
\text { school }\end{array}$ & $\begin{array}{c}\text { southern } \\
\text { school }\end{array}$ & $\begin{array}{c}\text { Comprehen } \\
\text { sive } \\
\text { university }\end{array}$ & $\begin{array}{c}\text { Vocational } \\
\text { college }\end{array}$ \\
\hline $\begin{array}{c}\text { Instructor created } \\
\text { section competition } \\
\text { Graphicdesign } \\
\text { competition }\end{array}$ & 117 & 43 & 14 & 146 \\
$\begin{array}{c}\text { Mechanical design skills } \\
\text { contest }\end{array}$ & 161 & 138 & 46 & 253 \\
Innovation competition & 291 & 132 & 126 & 178 \\
\hline
\end{tabular}

mple data display:(1). The difference between teaching mode and teaching mode of engineering colleges is obvious, showing that teachers in the north are more motivated to participate in the competition than the southern ones. (2). Teachers in vocational schools are more hands-on, and comprehensive university teachers are more willing to study theoretical studies. The teaching mode and courseware production are not highly motivated, and the difference is more than 90\%. 3 . Teachers' ability to guide students' competitions and students' enthusiasm for participation in the competition is higher than that in the north, with the highest proportion of winners reaching $20 \%$, and at least $10 \%$. 4. In all kinds of competitions, vocational colleges have significantly more awards than undergraduates (comprehensive universities), with the maximum difference reaching $80 \%$ and the minimum difference of $10 \%$.

According to the summary of statistics, the data analysis results are shown in figure 1:

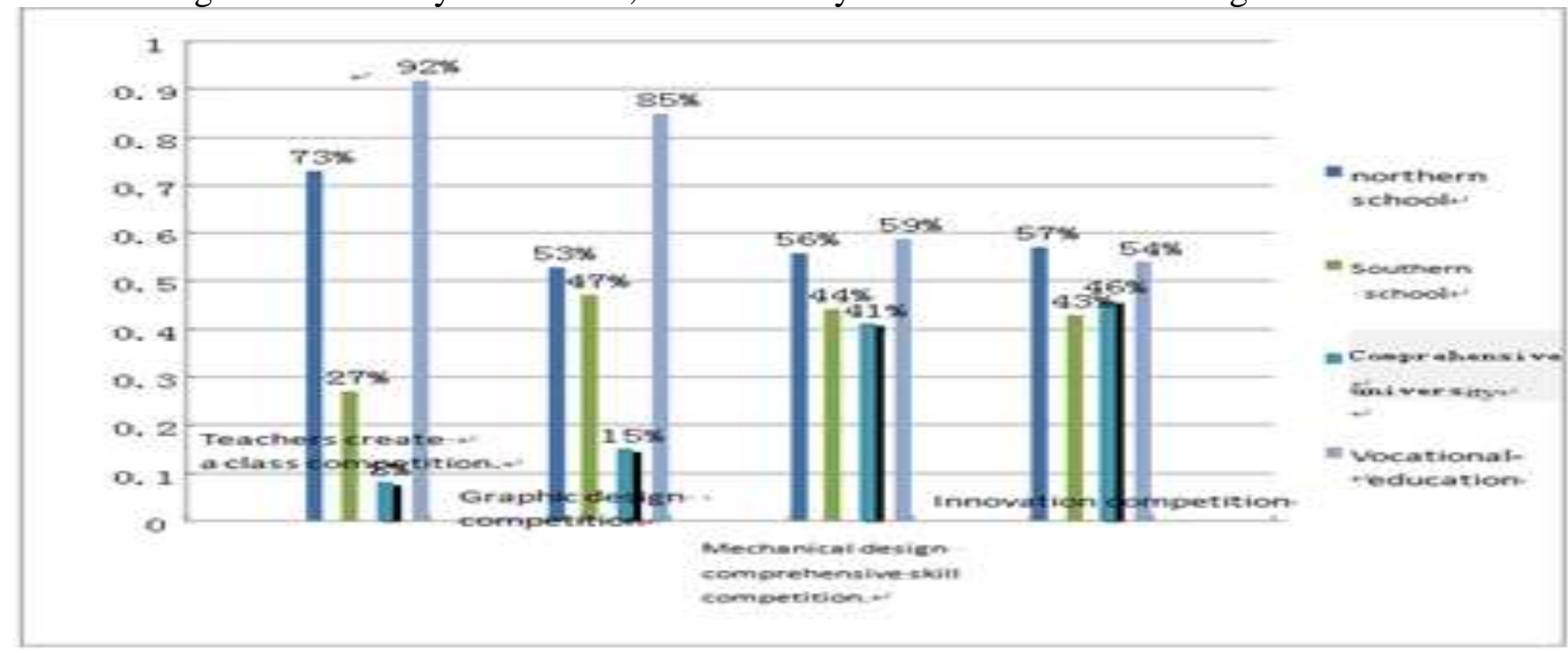

Figure 1 The percentage of innovative games Comparison chart

These data contrast, we found that the influence teachers' teaching methods and teaching content, 
teaching mode directly affect the teachers and the students' practical ability, match the right of all types and at all levels become a lap teaching pattern reform and the practice ability raise bridge, and the game itself is also university-enterprise cooperation platform depth fusion, thus, we take the automobile service engineering for research entities, constructing innovative teaching mode reform, practice behavior, build "school - $\quad$ enterprise -competition","school-competition-enterprise","enterprise-competition-school" closed-loop collaborative innovation development platform.

\section{Reform research and practice of innovative teaching mode}

In recent years, with the development of economy and the prosperity of automobile industry, the automobile industry has become the pillar industry of national economy, which plays an important role in the economic and social development of China.The automotive aftermarket,which is built around automobile sales, use and maintenance, has gradually become a promising field. Therefore, an urgent need to the number of more innovative application of automobile service engineering and technical personnel, which is the professional to carry out the integration education personnel training mode of engineering education strong demand environment and application background.

The scale of the automobile service industry is expanding rapidly,and the demand for advanced application-oriented technical talents is surging, and it is the goal of the enterprise to obtain high-quality talents that meet the needs of the enterprise. Some enterprises have begun to explore new ways to recruit talents, participate in the cultivation of college students, and even adopt customized training. Colleges and universities, on the other hand, the talent training scheme set up makes the formality of talents cultivation, theory course curriculum for the large space, and often miss out on these training objectives, combined with the teaching process and the "lost" of the enterprise, many factors may make it harder for graduates to become the enterprise needed to "talent", graduates unable to dock with the enterprises "zero distance". Therefore, we put forward the "training mode of professional talents for automobile service engineering based on the fusion of production and education".

research on training goal setting. The rise and development of automobile aftermarket is the inevitable outcome of the development of social productive forces. Buy cars mean more spending is just beginning, on the need to periodically refueling, maintenance, inspection, insurance, replacement of various parts, pay various fees, etc., once the accident, also involves the rescue, trailer, claims, etc. Spending on cars is lifelong, until the car is scrapped and disintegrated, so the consumption of a car is far greater than the price of a car. Automobile service engineering professionals focus on the "aftermarket", and the rapid development of the aftermarket requires a large number of automotive service engineering talents.

To better adapt to the current car market after the "engineering consciousness, engineering quality and engineering practice ability strong innovative engineering and technical personnel of the application of the status quo of automobile service engineering on personnel training, need to draw lessons from the successful experience of the advanced countries in the world of higher engineering education, through close cooperation with industry companies, to train cars with solid technology, marketing and trade theory foundation, acquire a knowledge of modern information technology and management, familiar with relevant laws and regulations, engineering knowledge, knowledge service and knowledge trade into an organic whole, have" will understand technology, management, good service "of the engineering quality, and to be able to do project work in the field of advanced applied talents.

pioneering the practice of modern apprenticeship training. Automobile service engineering as a cross subject of engineering and management, the main focus of starts, car rolled off the production line into the user group of whole process until the vehicle become a waste, a project is currently active research areas. Based on the field of theory teaching and practice teaching reform, use modern apprenticeship way, is the traditional way of apprenticeship training and teaching mode, the combination of modern school take their respective strengths and learning theory is not as entry-level, learn to hands-on practice is the entry-level, at all levels to participate in all kinds of 
competition is the premise of this style of culture industry introduction, to adapt to the steam service industry talent demand.

(1).Establish a professional steering committee, establish external training and practice bases, and cooperate with the training mode.School-enterprise cooperation can be jointly set up by the school teachers and the cadre of enterprise experts to form a professional steering committee to jointly develop the school-enterprise cooperation talent training program. Aiming at automobile service engineering, the course setting, teaching link and teaching method can be improved.(2).School-enterprise entity cooperation model. Schools and multi-party enterprises sign school-enterprise cooperation agreement, students can enter the enterprise for practical training. Enterprises can provide a certain amount of teaching resources according to their own situation, and provide teaching materials, teaching AIDS, teaching equipment, etc. The school cooperate with the enterprise, participate in the enterprise production practice.(3).Model of enterprise employee admission. Enterprises can send employees to school, on the one hand, continue education to improve the overall quality of employees;On the other hand, the school can hire enterprise backbone experts to teach in the school, so that the school and the enterprise are more closely related, so that the students' professional quality can be improved continuously.(4).Practical operation mode of students. Students practice in the training mode reform diversity, diversity of teaching mode, by the theory of teachers' teaching practice, students in-depth auto service enterprises of the actual field practice, experience in the service of technology, the relationship between knowledge, learn to apply.

practice the extension of "practice teaching + participation competition". Strengthen the practice teaching link,strengthen the internal and external practice, the training base construction, actively participate in all kinds of competitions, highlight the practical effect in the talent cultivation of the important position.

(1). Take the road of practice teaching of "teaching integration and school-enterprise interaction". It is the core and most effective way to cultivate application-oriented talents based on ability and social needs. University-enterprise cooperation is to exercise the student practice ability, the important way of cultivating applied talents, to provide practice platform to train applied and technical engineers, shortens the students from the school to the adaptation of the enterprise, to speed up the students' role transformation from students to the technician, meet the demand of the enterprise of talent cultivation. Build, can quickly to adapt to the auto service industry development up to jobs and innovation of practical teaching system of engineering and technical personnel, strengthen the contact with the enterprise or industry, strive to cultivate the students' engineering practical ability, in university-enterprise cooperation platform, building diversified practice + competition system.(2).To build a collaborative innovation platform of "cooperation between production and education integration and school-enterprise competition". The creation of collaborative innovation platform enables universities to grasp the pulse of talent cultivation in the industry. On the one hand, colleges can closely with auto service class enterprise demand of choose and employ persons, with the support of collaborative innovation platform and more auto service enterprises jointly develop auto service professional talents [3-4]. On the other hand, we should give full play to the guiding role of science and technology competition and integrate it into the regular teaching of colleges and universities to form a good interaction. In this way, the training of automobile service professionals in colleges and universities not only conforms to the industry's production practice demand but also has professional competitive ability.Fusion, competition between colleges education cooperation pattern is emerging in recent years, through the cooperation between colleges and enterprises, let the students to enter the work ahead of time scene, guide students to play forward thinking, according to the requirements of the job market, more true for sex study. Cooperation pattern is through the way of joint schools and enterprises, to student's study and daily production into the unified specification, on the one hand, with the students in learning advanced concepts to guide the factory in the line of teaching, reforming the fruitful production, will also be some experiences and lessons of daily production factory, in the form of competition practice training is passed to the students, let students study time has been to understand and grasp 
the enterprise the related operation mode and the way of daily work, let the students from the psychological and physical work life to prepare for the future.(3). Construction of "1.5+1.5+1" training system for automobile service engineering of qiqihar university. Refers to in the four years of university, 1.5 the main platform of "categories",before learning mechanical theory courses and related experiments and practice teaching of the campus, the next 1.5 years professionally, auto service professional course, the rest of the 1 year enterprise practice, practice and graduation design link. Take the employment-oriented internship, graduation thesis or graduation project based on the actual project of the enterprise. The combination of theory and practice can promote the ability of analyzing problems and solving problems, and improve students' innovative consciousness, so as to promote the development of students' employability.(4). Implement the dual tutorial system of teaching and competition guidance, and improve the practice ability of teachers and students. In the dual mode of "bringing in part-time teachers" and "teacher education", a "double teacher" teacher team with full-time teachers in the school and auxiliary teachers in the field of external engineering is set up.On the one hand, from the cooperative enterprises employ professional technical backbone to school part-time faculty, for teachers to cooperative enterprises for training and technical advisory services, through the real scene to solve problems, improve skills. We will send teachers to famous colleges and universities in China regularly to learn more about the frontier of science and technology at home and abroad. Employ enterprise senior engineer for outside, on the other hand, teacher, during the field work students, implement the "double tutorial system", namely the joint school teacher and mentor to guide students to complete professional core courses and graduation design, allows businesses to tutor students all the field work, improve the students' practical ability.(5). Establish theoretical courses and practice course assessment process model. Change the traditional theory of course assessment way, turn into the classroom, according to the professional automotive service special, adopt practical demanding curriculum theory procedural examination and appraisal and practice way; To meet the requirements of talents, it also conforms to the national automobile industry qualification examination model, and establishes the information teaching assessment mode of "cloud class" and "cloud textbook" [6-7]. Implement the introduction of new examination mode, practice assessment division, realizing the process assessment and qualification examination at the same time coordinate is appraisal standards of the state, improve talent practice ability, improve the employment rate.

\section{Build a platform for collaborative innovation and development of school, competition and enterprise closed-loop}

"Relying on the industry to run a professional service industry" is the philosophy that the higher education education integration should adhere to. Practical training teaching is arranged in terms of "cognition, single skill competition, integrated simulation, enterprise top post, project real operation" and other related stages.

Undergraduate colleges is the main carrier of teaching theory, to establish a profound cooperation office of teaching innovation model, form a "school-enterpris-competition", "school-competition-enterprise", "enterprise-competition-school" closed-loop collaborative education system. As shown in figure 2 . 


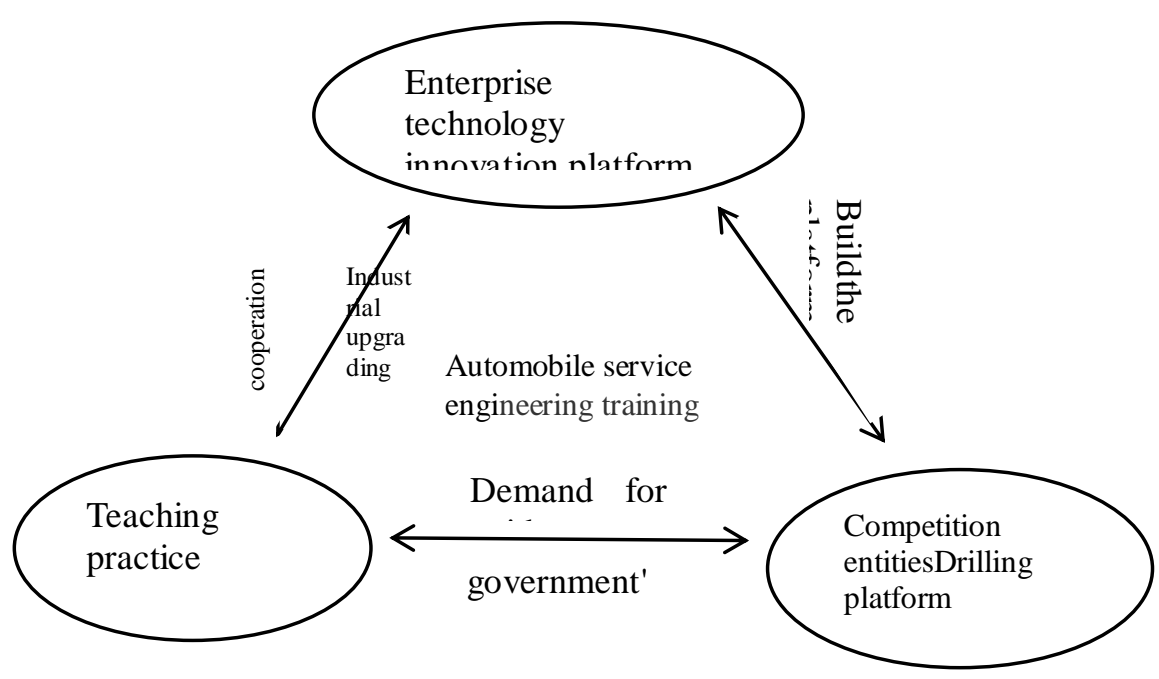

Figure 2 closed-loop collaborative education system.

(1). the students in the enterprise, the field work of course practice to obtain information and production capacity to participate in the competition, competition text and actual combat experience, and then to graduation design and writing paper, in the process, the formation of the college and enterprise cooperation mechanism of talents training.(2). enterprises in the form of "studio" in the school to create real workplace environment, namely business incubator, lets the student can directly involved in every link of the operation of the enterprise can directly contact to the related industries operate, technical process and the latest technology trends.(3).the enterprise real project through the enterprise to carry out the special competition, the government to carry out the course contests, institutions of higher learning to carry out academic competition, the enterprise need, department of education to guide into teaching, the students to participate in project design, operation and so on each link.

Build government policy support,school-enterprise cooperative education, industry-university-research cooperation development platform, innovation culture mode. To make the different social division of labor synergize in the aspects of function and resource superiority,such as scientific research,education, production and other fields, to realize the connection and coupling of technological innovation at different levels and depths. Involve depth industry enterprises in the whole process of talent training, the co-construction and sharing practice base, common design talent training plan,enterprise personnel to undertake teaching and practice teaching tasks, formed "platform, resource sharing, achievement sharing" mechanism of sustainable development.

\section{Conclusion}

In this paper,through a lot of research, combining the reality of production line of choose and employ persons, learn auto repair technicians and management staff,racing etc data and analysis to find the undergraduate course education mode reform needs to solve the key problem, has been clear about the depth of fusion education to cultivate "understand technology, will begin, will be written" talents as the goal, strive to highlight in talent training mode of "four combinations": professional theory knowledge and practice, teaching and competition to participate in teaching entrepreneurship education, professional education and innovation, the combination of value guidance combined with ability training.Research teaching mode reform and constructing university-enterprise cooperation, synergy and educating a closed-loop development platform, and can cultivate solid learning theory knowledge, good at written summary data, strong ability of a new generation of craftsmen, shorten the graduates enter the enterprise to adapt to the cycle, which can meet the demand of era, show the features of new engineering personnel training mode. 


\section{Acknowledgements}

Higher education teaching reform research project of heilongjiang province (SJGY20170374)

Major project of the research on teaching reform of Qiqihar University(2017092)

\section{References}

[1] Zhuo Tao ,Haofeng Jiang.the choice of innovation development path for automobile majors in higher vocational colleges under the integration of teaching and education $[\mathrm{J}]$. Automobile maintenance and repair, 2016.4:86-87.

[2] Taihua Jia. Analysis on the status quo and training mode of automobile service engineering talents [J]. Course education research.2016, (05) : 250-251.

[3] XiaoliuZhong, Shuiqiang Song, Llizhen Jiao . Research on teaching design based on flipped classroom in information environment [J]. Open education research,2013,(02):58-64.

[4] Yannian Chen, Changqing Zhou, Zhu ping Wu . The connotation and realization approach of teaching fusion $[\mathrm{J}]$. Chinese university science and technology, 2014(08) : 40-42.

[5] Juan Han. An exploration of the implementation of the training program for professional talents in automobile service engineering oriented by industrial demand [J]. Automobile practical technology, 2016.11:1-3.

[6] Yinghui Li , Min chai Hao , Yingxiu Shao. Brief introduction of informationization teaching reform based on blue ink cloud class and cloud textbook [J]. Journal of shijiazhuang vocational and technical college, 2017, (08) :60-65.

[7] Shufeng Jiang, Shang Liu, Cheng Xu. Reform and practice of the undergraduate teaching management model based on major categories of enrollment [J]. Asia-pacific education,2015,(06):102-104.

Author introduction. jiang shufeng (1979-), female, heilongjiang qiqihar, associate professor, master, engaged in teaching mode research, Research on reverse engineering and data mining. E-mail:474118867@qq.com 